Archivos de

Ciencias

Educación
Archivos de Ciencias de la Educación ISSN: 2346-8866

revistaarchivos@fahce.unlp.edu.ar

Universidad Nacional de La Plata Argentina

\title{
Freire en Finlandia: trayectorias de la presencia de Paulo Freire en el Norte global
}

\author{
Suoranta, Juha; Tomperi, Tuukka \\ Freire en Finlandia: trayectorias de la presencia de Paulo Freire en el Norte global \\ Archivos de Ciencias de la Educación, vol. 13, núm. 16, 2019 \\ Universidad Nacional de La Plata, Argentina \\ DOI: https://doi.org/10.24215/23468866e069
}

Atribución no comercial compartir igual (CC BY-NC-SA) 4.0 
Dossier: A 50 años de Pedagogía del Oprimido: lecturas en torno al legado de Paulo Freire Freire en Finlandia: trayectorias de la presencia de Paulo Freire en el Norte global Freire in Finland: trajectories of Paulo Freire's presence in the global North

Juha Suoranta

DOI: https://doi.org/10.24215/23468866e069

Facultad de Ciencias Sociales, Universidad de Tampere,

Finlandia

juha.suoranta@tuni.fi

\author{
Tuukka Tomperi \\ Facultad de Educación y Cultura, Universidad de Tampere, \\ Finlandia \\ tuukka.tomperi@gmail.com
}

Recepción: 30 Agosto 2019

Aprobación: 02 Diciembre 2019

\title{
RESUMEN:
}

En este artículo nos preguntamos si el pensamiento de Paulo Freire tuvo alguna influencia en Finlandia. eExiste una tradición reconocida de la pedagogía freireana en este país nórdico? Para dar respuesta a esta pregunta, trazamos la trayectoria de la recepción del pensamiento de Freire en las últimas décadas. Concluimos finalmente que, a pesar de que su impacto directo no se haya generalizado, ha habido múltiples e importantes conexiones y repercusiones del mismo. En términos más generales, vale la pena resaltar que la crucial renovación del sistema educativo finlandés que tuvo lugar desde fines de la década de 1960, fue contemporánea al espíritu freireano de justicia social y educativa. Nuestra contribución es histórica y teórica en su abordaje y metodología. La misma está basada en una profunda revisión de la literatura educativa finlandesa desde comienzos de 1970 hasta los años 2000. Para ayudarnos en la búsqueda de ejemplos de la presencia de Freire en el discurso pedagógico finlandés, también nos servimos de nuestros contactos con educadores de adultos veteranos en Finlandia. Finalmente, también recurrimos a nuestros trabajos previos sobre el tema.

Palabras ClaVe: Paulo Freire, Finlandia, teoría e historia de la educación, educación para la justicia social.

\section{ABstract:}

In the article, we ask whether Paulo Freire's thinking has had influence in Finland. Is there a recognisable tradition of "Freirean" pedagogy in our Nordic country? To answer, we outline the trajectory of Freire's reception during the decades. We conclude that even if the direct impact has not been widespread, there have been many important connections and echoes. More generally, it is worth perceiving that the crucial renewal of the Finnish educational system since the late 1960's was parallel to the Freirean spirit of educational social justice. We end by discussing what significance Freire's pedagogy has in Finnish educational world today. Our contribution is historical and theoretical by approach and methodology. It is based on extensive review of Finnish educational literature from the early 1970's to 2000's. To help us find examples of Freire's presence in Finnish pedagogical discourse, we have also used our many contacts to veteran practitioners of adult education in Finland. In addition, we have been able to rely on our prior work on Freire.

KEYwORDS: Paulo Freire, Finland, educational theory and history, education for social justice.

\section{INTRODUCCIÓN2}

Paulo Freire fue ampliamente reconocido alrededor del mundo a fines de los años 60'. Las campañas de alfabetización, así como también su exilio y su trabajo en propuestas radicalizadas de educación en Chile, y sus lecciones en los Estados Unidos, habían llamado la atención. Como es sabido, las campañas de alfabetización en las que participó Freire y su teoría educacional fueron retomadas y puestas en práctica desde una temprana etapa en muchos países, particularmente en América Latina y África. Al finalizar la década y en los principios de 1970, numerosos textos que incluían las ideas de Freire fueron publicados en portugués, español e inglés. 
Sin embargo, la investigación más exhaustiva sobre su trabajo no comenzó hasta los años 80', particularmente en Brasil, a donde había retornado en ese momento, y en Estados Unidos, donde muchos investigadores hispanohablantes y lusófonos habían establecido cercanos lazos académicos. ${ }^{3}$

Pedagogía del oprimido y los primeros escritos de Freire fueron traducidos a distintos idiomas desde fines de 1960. Particularmente, Pedagogía del oprimido ganó su significación más amplia a través del debate que tuvo lugar dentro de la teoría crítica de las ciencias sociales y humanas durante la segunda mitad de la década de 1960. La discusión focalizó en el rol y el impacto social de las ciencias sociales y educativas, y sus intereses de conocimiento en particular. ${ }^{4} \mathrm{El}$ debate crítico en las ciencias sociales estuvo estrechamente vinculado con los nuevos movimientos políticos de los años 60 , y quizás más fuertemente al movimiento estudiantil radicalizado.

Como caracterización general, se puede decir que el nombre de Paulo Freire y sus ideas generales de pedagogía crítica fueron ampliamente reconocidas en Finlandia entre las décadas entre 1970 y 1990, pero sus trabajos raramente fueron leídos, y sus ideas fueron usualmente conocidas solo de modo superficial. La situación en Suecia, el país vecino, fue algo diferente gracias a las traducciones de sus principales libros en los años 70. En Finlandia, el interés original en Freire se basó en los movimientos de activismo social de los años 60 y los tempranos 70 - siguiendo patrones similares a Occidente. Este interés se fortaleció por las preocupaciones que rápidamente crecían en Finlandia sobre los asuntos latinoamericanos. En los años 70' y 80' las ideas de Freire tuvieron lugar principalmente en el campo de la educación de adultos no formal. La investigación académica sobre el brasileño no se consolidó hasta finales de los años 90 y principios de los años 2000.

\section{La recepción de Freire en Finlandia: vista general}

En Finlandia, también, los primeros intereses que Freire despertó estaban basados en los movimientos sociales de los años 60' (movimientos radicalizados de izquierda, de trabajadoras y trabajadores; insurgencia estudiantil; movimiento de liberación de la mujer y el feminismo; movimientos de jóvenes, por los derechos civiles, por los derechos de las niñas y los niños, por la paz; tercermundismo), o vinculados con ellos. Además, la preocupación general en los asuntos latinoamericanos comenzó a crecer en Finlandia a partir de dicha época. El auge de esto último fue causado por el golpe militar en Chile. En Finlandia y otros países nórdicos, se creó un destacado movimiento de solidaridad y apoyo para la oposición al golpe en dicho país. Siguiendo el espíritu de esta solidaridad, al cabo de unos meses, más de 20.000 finlandeses se unieron a la Sociedad de Amistad Finlandia-Chile que fue fundada en 1973 (Pirttijärvi, 1998). ${ }^{5}$ Los diplomáticos finlandeses ayudaron a las víctimas de la persecución política a escapar de Chile hacia Europa. Finlandia recibió alrededor de 200 refugiados chilenos y, en verdad, ellos fueron los primeros refugiados políticos recibidos por decisión gubernamental finlandesa (Hiilamo, 2010).

El interés finlandés en los asuntos latinoamericanos se focalizó en ámbitos tales como la música, la literatura y la política - a menudo combinando las tres, como en el caso del movimiento llamado "La nueva canción". Tras un breve período, había una considerable cantidad de panfletos, artículos y libros traducidos sobre Latinoamérica. Para la nueva (y mayoritariamente joven) izquierda política, los debates del movimiento antiimperialista en Latinoamérica se convirtieron en uno de los puntos centrales de referencia y de experiencias compartidas.

Para mencionar algunos ejemplos con el propósito de dar una idea de la vividez de la actividad políticocultural al momento: en 1966 se creó la independiente (y abiertamente izquierdista) compañía de discos "Love Records", que se especializaba en música alternativa y de protesta (y que publicó la mayoría de los discos de La nueva canción en Finlandia). Su disco Lautanen Guatemalan verta ("Un plato de la sangre de Guatemala", una referencia a un poema de Pablo Neruda) fue la primera publicación de $L a$ 
nueva canción en Finlandia, seguida de muchas otras ${ }^{6}$. Por otra parte, hubo numerosas traducciones de prosa y poesía latinoamericanas a fines de los años 60' (Gabriel García Márquez, Carlos Fuentes, Miguel Ángel Asturias, etc.). Notables publicaciones de libros de aquel tiempo, incluyen: Kolmas maailma. Uutta proosaa espanjankielisestä Amerikasta (1966, "Tercer mundo. Una colección de la nueva prosa hispanoamericana"), Kello 0. Latinalaisen Amerikan runoja ja runoelmia (1969; "0 en punto. Poesía desde Latinoamérica"), Olli Alho, Latinalaisen Amerikan haaste (1969, "El desafío de América Latina”), Johan von Bonsdorff, Latinalainen Amerikka (1969, "Latinoamérica”), Jyrki Lappi-Seppälä, Toinen Amerikka - kolmasosa kolmatta maailmaa (1969, "La Otra América - Un Tercio del Tercer Mundo"), Matti Rossi, Väkivallan vuosi: Matka Latinalaiseen Amerikkaan (1970, "El Año de la Violencia: Un Viaje en Latinoamérica”), Sven Lindqvist, Heittovarjo. Latinalainen Amerikka 1970-luvun kynnyksellä (1970, traducción de "La sombra: América Latina se enfrenta a los setenta"), André Gunder Frank, Kapitalismi ja alikehitys Latinalaisessa Amerikassa (1971, traducción de "Capitalismo y subdesarrollo en América Latina"), Osmo Apunen, Vaihtoehtona vallankumous (1971, "La revolución como una Alternativa"), Terttu Oroza, Bolivian päiväkirja (1971, "Un diario de Bolivia") - además de muchos otros libros finlandeses nuevos y traducciones realizadas oportunamente.

A pesar de las numerosas discusiones sobre asuntos latinoamericanos, y que muchos libros sobre esos temas fueron escritos y publicados como nunca antes (o después), el trabajo de Freire no fue traducido al finés en ese momento. Por otro lado, en Suecia, el país vecino, las enseñanzas de Freire habían ganado más atención tanto en la educación escolar como en la educación de adultos, y sus ideas fueron discutidas en la universidad y en la prensa. Las traducciones suecas de los libros de Freire fueron publicadas tempranamente: Pedagogik för förtryckta (1972, Pedagogía del oprimido), Kulturell kamp för fribet (1974, Acción cultural para la libertad), Utbildning för befrielse (1975, La educación como práctica de la libertad), y Pedagogik i utveckling (1978, Cartas a Guinea-Bissau). Freire, incluso, fue introducido e inmortalizado en la escultura de Nye Engström Efter badet ("Luego del baño", 1976) junto con Angela Davis, Pablo Neruda y Mao Tse-Tung, en el distrito de Västertorp del Estocolmo suburbano en Suecia. ${ }^{7}$

Las traducciones suecas de los trabajos de Freire también tuvieron cierta influencia en Finlandia. El sueco es la segunda lengua oficial del país, existe una importante minoría sueco-parlante, y Finlandia ha tenido estrechos vínculos históricos y culturales con Suecia. En Finlandia, sin embargo, las ciencias de la educación no estuvieron en el centro de los debates más radicalizados del ámbito universitario, por lo cual la actual tradición de investigación freireana no había nacido aún. En los años 60' y 70' las conexiones científicas al mundo iberoamericano fueron establecidas principalmente a través de las ciencias políticas y sociales. Particularmente importante en esa época fue el grupo de investigación TRICONT (abreviación referida a "los tres continentes"), que publicó una serie de libros panfletos llamada Kolmas maailma ("Tercer Mundo") entre los años 1968 y 1972, y trajo muchos asuntos del Tercer Mundo -especialmente investigaciones sociales, políticas y de desarrollo de Latinoamérica- al foco de atención académica. En educación, las ideas de Freire tuvieron impacto principalmente en círculos no académicos de debate sobre educación de adultos no formal y grupos de aprendizaje libre y auto-motivado. Una paradigmática forma de esta práctica educativa son los círculos de estudio en donde se reúnen personas alrededor de un tópico de su propia elección, usualmente sin una o un docente.

Aún así, muchos de las y los cuales se encontraban estudiando educación en los años 70' conocieron las teorías de Freire, que algunas veces fueron intensamente discutidas en las aulas universitarias. Aparentemente, Freire se volvió conocido en Finlandia originalmente a través de discusiones, lecciones, seminarios y enseñanzas en las universidades y en la educación de adultos no formal, pero no en publicaciones. Con el correr de las décadas, muchos investigadores de educación de adultos se han referido a Freire en sus textos pero sorprendentemente pocos estudios han focalizado principalmente en su trabajo, o han usado el mismo como un punto inicial para la aplicación pedagógica. Además de varios resúmenes cortos y generales, 
esto incluyó un pequeño número de artículos, algunos estudios aplicados, y una escasa variedad de tesis de grado.

No fue hasta los años 2000 que el estilo freireano de la pedagogía crítica ganó una atención académica más profunda. La primera investigación publicada sobre Freire, una tesis doctoral, apareció en el año 2000, y la traducción finesa Sorrettujen pedagogiikka (Pedagogía del oprimido) fue publicada en el 2005. Estas publicaciones fueron acompañadas y seguidas por muchos otros trabajos y traducciones de pedagogía crítica. El interés en Freire y en diferentes tradiciones de la pedagogía crítica ha ganado un considerable impulso durante los años 00' y 10' en Finlandia. ${ }^{8}$ Las más importantes de estas publicaciones son: la tesis y disertación de posgrado de Aino Hannula (1998, 2000), de las cuales la segunda fue el primer estudio en profundidad de Freire en Finlandia, y así el punto inicial para una exitosa investigación; la traducción de Pedagogía del Oprimido(Freire, 2005) con introducción y epílogo fineses (Tomperi, 2005; Tomperi \& Suoranta, 2005); y la muy reciente y biográficamente conducida investigación monográfica por Juha Suoranta (Suoranta, 2019). ${ }^{9}$

Existe una anécdota interesante en la traducción finesa de Pedagogía del oprimido. El manuscrito de la traducción finesa fue inicialmente basado en la versión inglesa de la obra. Sin embargo, durante la revisión y edición de la traducción, el editor (siendo uno de los autores de este texto, Tuukka Tomperi) usó las versiones portuguesa, española e inglesa del libro, y realizó comparaciones entre ellas, con el propósito de encontrar formulaciones que se adecuaran de la mejor manera posible al lenguaje finés y sirviesen para los lectores finlandeses, y aún así sostenerse fiel al texto original de Freire. Es así que la versión finlandesa de Pedagogía del oprimido no es exactamente la misma en comparación las versiones en ningún otro idioma. Esta traducción significó un punto de inflexión en la recepción finlandesa de Freire. Atrajo mucho la atención y estimuló nuevas y vibrantes discusiones e intereses con su extensiva introducción y epílogo que destacan, valúan y popularizan las ideas freireanas para las lectoras y los lectores finlandeses.

En el 2007 uno de los autores de este texto (Juha Suoranta) fundó el Centro Paulo Freire - Finlandia para "promover la investigación, organizar eventos y colaborar con docentes, educadoras y educadores, y trabajadoras y trabajadores culturales en el desarrollo de actividades de orientación freireana". El centro fue, y hasta nuestro conocimiento sigue siendo, el único en los países nórdicos dedicado al pensamiento freireano. La conferencia inaugural del centro fue realizada por el profesor Peter McLaren. En 2017, el Centro Paulo Freire - Finlandia fue unificado con Krigo, una asociación de educadores "que promueve las prácticas pedagógicas y los procesos educativos colaborativos con el propósito de generar esperanza y reducir el sufrimiento humano, la explotación y la exclusión en niveles individuales, comunitarios y societales". ${ }^{10}$ En los últimos años, las actividades del Centro Paulo Freire - Finlandia han estado mayormente estancadas.

Cuando se escribe sobre Freire en un contexto educativo en Finlandia, el énfasis suele estar más en sus perspectivas didácticas y metodológicas que en su filosofía social y educacional. Ciertos conceptos básicos como "diálogo" y "educación problematizadora" -ésta última a menudo interpretada como "aprendizaje basado en problemas"- han sido fácilmente identificados y vinculados con otras corrientes de la pedagogía contemporánea y de la psicología del aprendizaje. ${ }^{11}$ Por otro lado, los aspectos más visibles en términos políticos y filosóficos del pensamiento freireano han sido algunas veces percibidos como oscuros y contradictorios (Tuominen, 1975, p. 165). El profesor de educación Juhani Suortti, sin embargo, señala un importante recordatorio:

Cuando alguien reclama que él [Freire] está escribiendo sobre sus principios de forma vaga, es, en realidad, un asunto de no ser capaz de hablar más objetivamente sobre todas las diferentes condiciones sociales, porque carecemos de un lenguaje apropiado para ello. El problema con la filosofía de Freire es que las personas que interpretan sus ideas no entienden las circunstancias bajo las cuales él creó su teoría y por ese motivo le otorgan demasiado peso a la expectativa de encontrar cierta teoría oculta (Suortti, 1999, p. 181).

Puede decirse que el pensamiento de Freire toma lugar y se vuelve realidad no solo en sus textos, sino por sobre todo en las innumerables prácticas de alfabetización y la educación básica, a través de las cuales 
se ha cultivado la conciencia de las personas para con su propia posición social. Las enseñanzas de Freire han sido utilizadas en trabajos educacionales en Finlandia tanto en prácticas no formales de educación de adultos como también, aunque con diferentes temáticas, en la escuela primaria, por ejemplo, en la literatura y la educación artística. Las ideas de Freire fueron traídas a la educación de adultos finlandesa en forma de varios usos del aprendizaje emancipatorio. Han sido utilizadas, por ejemplo, en tipos de educación de adultos que apuntan al aprendizaje innovador y transformador, basado en la reflexión crítica y el análisis consciente de las estructuras opresivas de la sociedad y sus reflejos en las expresiones subjetivas. Las organizaciones finlandesas de educación de adultos, como los centros de educación de adultos y los centros de estudios, con orientaciones de izquierda, han mantenido y utilizado las ideas de Freire. Entre ellas están TSL Työväen sivistysliitto ("Asociación de Educación para las Trabajadoras y los Trabajadores”), KSL Kansan sivistysliitto ("Asociación de educación popular") y DSL Demokraattinen sivistysliitto ("Asociación democrática de Educación "). Esta última, una pequeña organización marxista de educación, ha publicado un folleto de 43 páginas Toimintaan Freiren kanssa (“Acción con Freire”, 2012).

En la pedagogía de la escuela común, las ideas freireanas han sido aplicadas especialmente en los intentos de incorporar los problemas de la vida cotidiana para revitalizar la enseñanza, el aprendizaje basado en preguntas, la enseñanza interactiva y la pedagogía dialógica. Sin embargo, también puede ser visto como un problema que la atención solamente se le preste al "método" de enseñanza de Freire - diálogo en sí mismo, sin la sociedad - y no al contenido y al propósito de su pedagogía, que es la naturaleza política de la educación y el objetivo de la emancipación política y la liberación. Esto ha sido conocido como la "domesticación" de Freire (Suortti, 1999). Un ejemplo de esta interpretación domesticada es la siguiente declaración del profesor finlandés de didáctica y prácticas de la enseñanza de la danza Eeva Anttila: "El problema es que sus ideas han sido usadas para fines políticos - que, a mi entender, nunca fue su propósito inicial" (Veiga, 2019). Sin embargo, la comprensión generalizada en la teoría crítica educacional es que la educación es siempre política y esto es especialmente así en el caso del pensamiento educativo de Freire (McLaren, 2000; Darder, 2018).

Por fuera de la alfabetización, la educación básica y la educación de adultos no formal, los principios pedagógicos de Freire pueden usarse en formas muy diferentes. Desde este punto de vista, es natural que haya más textos que toman a Freire como una inspiración, por ejemplo, en educación de medios de comunicación, pedagogía de la danza y educación artística, en lugar de estudios, presentaciones y comentarios propiamente sobre él (Anttila, 2003; Kotilainen, 2004; Suoranta, 2003; Lehtimaja, 2006). Debe notarse que no hay una investigación sistemática sobre la diseminación de la influencia de Freire en Finlandia. ${ }^{12}$ Sin embargo, como en el resto del mundo, las ideas de Freire han inspirado acciones prácticas y experimentales en varios proyectos educativos comunitarios, capacitaciones sindicales, proyectos de desarrollo de programas sociales, trabajos sobre participación juvenil, educación para la salud y muchos otros proyectos educativos que intentan elevar la conciencia crítica de las personas. En lo que sigue, tomamos una mirada más cercana sobre algunos de los usos finlandeses de Freire más reconocidos.

\section{Principales ejemplos de la influencia de Freire}

No se puede hablar de la recepción finlandesa de la pedagogía de Freire sin describir brevemente la larga e impresionante carrera educacional de Helena Kekkonen (1926 - 2014). Ella puede, sin dudas, ser reconocida como la primera persona en aplicar la educación emancipatoria de Freire en Finlandia. En su trabajo, el descubrimiento de las ideas freireanas tuvo lugar a principios de los años 70', cuando había abandonado su trabajo como directora en la Escuela Vocacional para Trabajadoras y Trabajadores de Laboratorios para dedicarse a novedosos proyectos en educación de adultos. ${ }^{13}$ El objetivo era identificar las necesidades educativas de las personas en su vida cotidiana. Educadores de adultos y docentes de la educación de adultos no formal, comenzaron a acercarse a las personas en sus entornos cotidianos sin esperar que ellas y ellos entren 
a las aulas. Estas ideas y métodos novedosos llevaron a Kekkonen a trabajar en prisiones, primero para enseñar ciencias naturales a los reclusos, y luego para empezar a organizar círculos de cultura con ellas y ellos.

Iniciativas experimentales y experiencias emergentes le demostraron a Kekkonen que los principios de Freire encajaban perfectamente en las realidades de las instituciones penales. Las circunstancias de la educación en cárceles eran caracterizadas por la discriminación social hacia los prisioneros, algo que muchos habían internalizado como una señal de su incapacidad y alienación. Kekkonen descubrió que el ejercicio interno de poder en una institución totalitaria era estructurado por la confrontación entre prisioneros y guardias. Además, los guardias a veces recurrían a prácticas arbitrarias. La dinámica social de las prisiones era entonces un claro caso de la relación entre opresores y oprimidos.

Los círculos de cultura se volvieron exitosos en una manera que sorprendió a Kekkonen misma. El autoestima de los prisioneros aumentó, se vieron inspirados por la literatura y las artes, y muchos de ellos encontraron su propia voz incluso en expresiones creativas y personales. Comenzaron a mirar su propia historia de vida y la sociedad alrededor suyo con nueva conciencia crítica. Al mismo tiempo, el sentimiento defensivo de compasión con uno mismo por ser una víctima de las circunstancias, fue reemplazado por un renovado sentido de responsabilidad y control sobre la propia vida. Los círculos de cultura fueron un punto de inflexión en las vidas de algunos participantes (Kekkonen, 1993). Este tipo de principio freiriano de pedagogía de la esperanza era característico en las actividades e ideas de Kekkonen.

Luego de sus experiencias en educación en cárceles Helena Kekkonen promovió los valores de Freire en diferentes roles en el campo de la educación de adultos en Finlandia. Ella trabajó, por ejemplo, como la Secretaria General de la Asociación Finlandesa de Educación de Adultos, como una educadora por la paz internacionalmente aclamada, y como Secretaria General del Instituto de la Educación para la Paz. Su ejemplo siempre transmitió un amor típicamente freireano por la educación, donde las palabras, acciones y realidades humanas estaban unidas y en armonía. Por su trabajo, recibió el premio de Educación para la Paz de UNESCO en 1981, el mismo que se le dio a Freire en 1986. Con respecto a la educación por la paz, también Leena Kakko siguió el camino que Kekkonen inició y vinculó su trabajo al pensamiento pedagógico de Freire (Kakko, 1988).

Otro ejemplo de una influencia más visible de Freire en Finlandia ha sido la investigación y la enseñanza que Leena Kurki ha realizado en el campo de la pedagogía social. Su extensa investigación se ha focalizado particularmente en las tradiciones educativas de Latinoamérica, la educación jesuita, la animación sociocultural, el personalismo de Mounier, y la teología y la pedagogía de la liberación (Kurki, 1991a, 1991b, 2000, 2002, 2005). Las similitudes entre la animación sociocultural (tanto la tradición francesa como la iberoamericana) y la pedagogía crítica de Freire son evidentes (Kurki, 2000). Según Kurki, "la pedagogía freireana de la liberación, como también el más amplio campo latinoamericano de pedagogía social, la metodología de acción social, es esencialmente animación sociocultural" (Kurki, 2000). Ambos tienen en sus raíces los movimientos de cultura y educación popular (Kurki, 2005).

Asimismo, las ideas de Freire a veces han influenciado proyectos finlandeses de cooperación al desarrollo y sus investigaciones, donde han apoyado especialmente aquellas aproximaciones que han sido llamadas "participación-acción" e "investigación-acción participativa". Marja-Liisa Swantz, educadora finlandesa, es reconocida por su desarrollo de estas aproximaciones en el mundo. En sus memorias, ha relatado sobre cómo familiarizarse con las ideas de Freire la ayudó a situar su trabajo de cooperación para el desarrollo y sus prácticas de enseñanza en Tanzania, dentro del amplio contexto político de dicho país. Esto la llevó a comprender que la educación está siempre conectada a asuntos políticos complejos. Swantz estaba particularmente interesada en la idea de que la educación y el desarrollo podían ser construidos en la base del propio conocimiento de las personas sobre sus situaciones de vida (Swantz, 2004). Con la confirmación que tuvo a través de las ideas de Freire, fue posible unir los ámbitos y esferas del conocimiento, inteligencia, reflexión, análisis, y experiencia práctica y personal: "Mi vida y mi trabajo fueron reestructurados en una nueva manera [a través de los pensamientos de Freire], y en mi experiencia ese período fue fructífero en 
todos los aspectos de mi vida" (Swantz, 2004, p. 263). Swantz también tomó nota de cómo las ideas de Freire diferían significativamente de la propaganda socialista usual del momento, que solo le hablaba a las masas: "Yo comencé a comprender que estas ideas [las de Freire] creaban una verdadera base para el desarrollo. Es posible desafiar a las personas como individuos tanto como comunidades al mismo tiempo, como individuos dentro de las comunidades, e incrementar la concientización. La comunicación entre las personas es clave para un nuevo tipo de conciencia social" (Swantz, 2004, p. 264).

Por supuesto, el trabajo de Freire también ha sido reconocido en los procesos finlandeses de alfabetización. La figura de Freire como un teórico de la alfabetización bajo ningún sentido se ha establecido completamente en el canon finlandés, pero se ha prestado más atención a sus escritos cuando la noción que enfatiza las conexiones entre alfabetización y concientización social se volvió más popular, además de las concepciones tradicionales y funcionales de ese campo (Raassina, 1990). En la perspectiva de Freire, la alfabetización no puede ser políticamente neutral, porque está atada a cuestiones de conciencia social crítica: "la conciencia crítica promueve un deseo de aprender a leer a escribir, y la alfabetización, en ese sentido, fortalece la conciencia crítica y crea condiciones favorables para la liberación de la opresión, apatía y fatalismo, y para que las personas cambien activamente su situación" (Raassina, 1990). En las investigaciones finlandesas sobre desarrollo sostenible, focalizadas en asuntos regionales, locales y globales, se han escrito muchos textos sobre el rol de los proyectos de alfabetización de Freire, particularmente en países africanos y latinoamericanos (Jauhiainen et al., 1984).

También pueden encontrarse referencias a Freire en estudios finlandeses de teología contextual. El foco de la teología contextual está particularmente dirigido a las realidades del Tercer Mundo, cuyas tradiciones socioculturales y religiosas han desafiado al universalismo académico europeo (Ahonen, 2004). Las revolucionarias teologías de la liberación latinoamericanas son particularmente reconocidas en Finlandia. ${ }^{14}$ Sus contenidos, prácticas e interpretaciones religiosas han emergido de la experiencia de la opresión, y se proponen "priorizar la defensa de los pobres y quitar las máscaras ideológicas de la religión, en vez de defender al Cristianismo como una institución (apologéticamente)" (Raunu, 2004). Muchas de las ideas originales de la teología de la liberación, desde el rol seminal de los pobres hasta el concepto de la praxis religiosa liberadora, como desarrolla el teólogo peruano Gustavo Gutiérrez, fueron desarrolladas junto con la filosofía educacional de Freire, e influenciadas por la misma (Raunu, 2004).

Es notable que las ideas de Freire estén arraigadas como una de las tradiciones teóricas en la investigación y enseñanza de la educación artística finlandesa. Un caso, por ejemplo, es la investigación artística de Lissu Lehtimaja sobre Freire. Ella también lo ha presentado en la más original e innovadora forma de introducir el pensamiento de Freire en Finlandia: un libro de cómic titulado Freiren kyydissä("Paseando con Freire", Lehtimaja, 2006). ${ }^{15}$ Otro ejemplo es la tesis de disertación de Liisa Söderlund en artes visuales, en la cual se aplica la teoría de Freire de opresión y liberación en su investigación-acción con las personas en situación de calle. Como parte de la investigación, las personas en situación de calle fotografiaron sus propias vidas y entornos cotidianos e interpretaron las fotos con la investigadora. Söderlund organizó una exhibición de fotos para inculcar conciencia en el público y los políticos municipales (Söderlund, 2020, próximamente).

Finalmente, debemos mencionar el "teatro del oprimido" desarrollado por Augusto Boal, porque es también muy conocido en sus diversas formas en Finlandia donde el teatro ha sido, históricamente, parte importante de la cultura (Riekki 1999; Paasonen, 2000). Boal fue un influyente docente brasileño inspirado por Freire y, desde los años 60', desarrolló aproximaciones a la comunidad del teatro con el propósito de guiar a las y los participantes o espectadores a reflejarse en sí mismos en las circunstancias, situaciones y problemas cotidianos de sus comunidades. El "foro de teatro" de Boal refiere a una presentación en la cual, después de una situación dramática de conflicto, los espectadores tienen la oportunidad de participar analizando y resolviendo la misma a través de la discusión y la actuación. Freire mismo menciona este tipo de dramatización en Pedagogía del oprimido, como una de las posibilidades de "codificar" los tópicos educativos. El "teatro invisible" de Boal, por otro lado, es un teatro callejero en donde las personas son provocadas en su vida 
cotidiana, impulsando la concientización y reflexión al crear escenas que difieren de las expectativas sociales comunes. Las formas participativas o comunitarias del teatro de Boal han sido usadas en Finlandia por grupos de teatro y en educación de teatro, pero también por animadoras y animadores juveniles, trabajadoras y trabajadores sociales, y activistas de organizaciones no gubernamentales.

\section{La importancia de Freire hoY y en el Futuro}

Así como ocurre en otros países, diversas prácticas educativas voluntarias y autogestionadas por organizaciones no gubernamentales (ONGs) en Finlandia representan el corazón de las investigaciones y producciones freireanas del presente. Para las educadoras y educadores de adultos freireanos, es muy importante el trabajo sobre temas tales como las redes cooperativas que se entretejen entre ONGs del norte y del sur, el desarrollo de acciones sociales multilingüísticas y multiculturales o la comunicación intercultural. Es evidente que los principios pedagógicos de Paulo Freire, desde la consciencia crítica del aprendizaje hasta la actividad auto-motivada así como el diálogo y la igualdad, se encarnan en el trabajo que realizan muchas ONGs en la promoción de la transformación social. Sin embargo, en algunas oportunidades, las ONGs trabajan demasiado formalmente y únicamente en sus oficinas, no pudiendo beneficiarse de las ideas de Freire quien, cuando trabajaba en las campañas de alfabetización, utilizaba el método etnográfico para familiarizarse con las condiciones de vida de las personas con las que trabajaba y aprender de ellas y con ellas.

La filosofía social y educativa de Freire también puede contribuir de manera crucial en la construcción de la resistencia a las tendencias neoliberales en la educación formal de adultos. En este sentido, su pedagogía crítica se contrapone con producciones recientes que enfatizan únicamente en la experticia técnica y las competencias, entendiendo a los educandos como clientes, a las educadoras y educadores como proveedores de un servicio educativo y a las instituciones educativas desde un enfoque empresarial. Desde el punto de vista freireano, el aprendizaje y la educación son vistas como procesos integrados en la sociedad y la cotidianidad de la vida humana.

Vale la pena reparar en que, incluso aunque la teoría e historia de la educación no sean el corazón de los programas de formación docente en Finlandia, se incluye Pedagogía del oprimido como uno de los escasos textos clásicos de teoría educativa que están presentes en los currículum de las facultades de educación (al menos como lecturas optativas). De esta manera las y los estudiantes han tenido la oportunidad de conocer algunas de las ideas freireanas y, tal vez, continuar profundizando en ellas por iniciativa propia. Junto con John Dewey y Jean Piaget, Freire es uno de los teóricos de la educación del siglo XX más reconocidos por las y los estudiantes finlandeses de educación, formación docente y ciencias sociales, incluso aunque muy pocos lo hayan leído realmente.

La docencia ha sido en Finlandia una carrera altamente cotizada y competitiva, lo cual hace que los procesos de selección e ingreso sean difíciles para las y los aspirantes. Aquellas y aquellos que finalmente quedan seleccionados para estudiar la carrera docente son usualmente quienes han tenido un trayecto exitoso en su propio paso por la escuela, la mayoría de ellas y ellos representantes de la clase media -parte del sector más privilegiado de la población. Por lo tanto, la presencia de la pedagogía crítica freireana en la currícula docente podría funcionar como una advertencia sobre la necesidad de que la educación sea vista desde la perspectiva de las y los oprimidos y las y los desfavorecidos. El trabajo de Freire ofrece una comprensión de lo que es principalmente importante en la humanidad y en los fundamentos de la educación. Su visión crítica recuerda a los y las futuros docentes que, mientras que algunos somos considerados ciudadanos de pleno derecho, otros son excluidos y la escuela no siempre juega un papel igualador entre los niños. Freire desafía la imagen típicamente idealizada de una práctica e investigación educativas que se suponen políticamente neutrales. Los ranking y comparaciones internacionales tales como PISA, deben complementar sus resultados con información proveniente de investigaciones con un interés crítico y emancipatorio que busquen entender la naturaleza política de las sociedades humanas. La naturaleza de la educación como fenómeno ético y político 
debe ser problematizada constantemente en la investigación y en las prácticas educativas. Este es uno de los principales aportes de la lectura de Paulo Freire.

En el debate educativo que tuvo lugar en Finlandia en el corriente siglo, a menudo se ha adoptado un actitud acrítica frente a la incorporación de las nuevas tecnologías de la información y la comunicación, dando por evidente su carácter necesario y beneficioso. Esta premisa suele vincularse perfectamente al argumento de que la principal tarea de la escuela y la política educativa es ayudar a la población a adaptarse a las normas del capitalismo global y tecnológico, y a la competencia económica. Desde el punto de vista freireano, el debate educativo también se ocupa de los modos -desde distintos tipos de concepciones y prácticas expertas- en los que las personas serán gobernadas y controladas en el futuro. Los usos y las posibilidades de las tecnologías de la información en las escuelas son una parte extremadamente importante de este cuestionamiento. ¿Acaso la economía impulsada por las tecnologías de la información crea nuevas divisiones sociales o existe una resistencia dentro de la propia cultura tecnológica hacia el totalitarismo económico? ¿Puede el uso de las tecnologías contribuir al pensamiento y las acciones críticas en lugar de aportar al conformismo con el presente orden mundial?

El pensamiento de Freire hace especial hincapié en la importancia de un sentido genuino de relaciones sociales libres y comunitarias, que se opongan a la tiranía económica. La migración interna de personas desde áreas menos pobladas a las regiones centrales y las ciudades es uno de los problemas que ha crecido en el último tiempo en la sociedad finlandesa. Las consecuencias problemáticas de estos cambios estructurales en la sociedad tienen especial repercusión en las escuelas, ya que las más pequeñas y menos pobladas se ven amenazadas por un inminente cierre. Tal como señala Freire, el derecho al acceso a las escuelas locales como cunas de genuinas relaciones comunitarias, debe ser defendido. Lo mismo aplica a escuelas en las grandes ciudades. Tanto las y los docentes como las y los estudiantes en dichas áreas tienen el derecho a un ambiente escolar decente, con clases razonablemente ajustadas en su tamaño y no demasiado pobladas. Por lo tanto, las escuelas pueden contrarrestar los problemas sociales y ser tierra fértil para la promoción de una ciudadanía participativa. Otra problemática actual y en prospectiva tiene que ver con la inmigración extranjera que se concentra en las grandes ciudades. En esa línea, el sistema educativo debe poder ofrecer una respuesta a los diversos problemas que la migración trae consigo y estar listo para flexibilizarse hacia formas más multiculturales. Si no se sostiene la capacitación permanente de los docentes esto se dificultaría, por lo cual la contribución de Freire sería muy significativa en este sentido. La perspectiva freireana en la educación multicultural nos hace tener presente que no se trata únicamente de una pregunta por el lenguaje sino también por la justicia social; no sólo un debate sobre cuáles serían los métodos pedagógicos más adecuados sino de una transformación dialógica de la sociedad.

En el reciente debate de la política educativa finlandesa, las voces críticas advirtieron que la educación no debe ser guiada por los valores del mercado (Tervasmäki \& Tomperi, 2018; Tervasmäki et. al., 2018). El pensamiento crítico no sólo se dirige hacia la dominación de la ideología económica, sino más generalmente, también ha desafiado la idea de someter a las escuelas a la racionalidad instrumental y aumentar las expectativas (e indicadores) de rentabilidad. Usando las nociones de Freire, podríamos decir que existe una rivalidad entre el "control anti-dialógico" que promueve la adaptación de las personas al régimen capitalista, y la "acción dialógica y liberadora" que intenta hacer significativa la vida humana. Lejos de dramatizar, estas dimensiones y voces son fácilmente identificable en los discursos del debate por la política educativa en Finlandia.

Aún hay múltiples preguntas y discusiones por ser resueltas entre estos bloques rivales. ¿Es la educación de adultos simplemente una necesidad forzada orientada a la capacitación laboral continua - en el marco del veloz desarrollo del capitalismo a través de los avances científico- tecnológicos? ¿ $\mathrm{O}$ resisten aún los ideales de una educación liberadora y una (auto)educación para el propio desarrollo personal? ¿Serán las habilidades técnico-económicas y los ideales de educación para el emprendedurismo los que determinen el currículum de la escuela del mañana? ¿O estará éste guiado por los renovados ideales de una ciudadanía 
activa y responsable? ¿Está la educación vocacional aún muy determinada por las exigencias de una economía capitalista que cambia velozmente? ¿O sobrevive la idea de la educación profesional liberadora, en cuyo núcleo está el empoderamiento de las personas y su derecho a la autodeterminación y el ejercicio de una democracia comunitaria en sus propios lugares de trabajo? ¿Quién tendrá el derecho pleno y el acceso a una educación de calidad en el futuro? ¿Serán erosionadas las ideas de un sistema escolar común y público dando lugar a que gran parte de las niñas y niños caigan en la marginalidad mientras los recursos se concentran cada vez más entre los sectores privilegiados? Estas preguntas continúan genuinamente abiertas y sus respuestas están siendo ensayadas constantemente. La dirección que las mismas vayan tomando también dependen de las y los educadores y sus sindicatos, del conocimiento que tengan de las políticas, las tendencias y las prácticas educativas; de cómo logren defender sus derechos y expresar sus perspectivas y preocupaciones. En todas estas cuestiones podemos seguir aprendiendo de Freire.

\section{EDUCACIÓN PARA LA JUSTICIA SOCIAL}

Como hemos demostrado anteriormente, el trabajo de Freire no pasó desapercibido en la producción de las ciencias sociales, humanas y educativas en Finlandia desde los años '70. Tal vez no sea una exageración decir que el legado de Freire ha formado parte de una corriente alternativa de pensamiento educativo en Finlandia, aunque nunca fue explícitamente parte de las corrientes más ampliamente aceptadas. Lo mismo aplica en el caso de la política educativa finlandesa. El pensamiento freireano ha tenido relativamente poco efecto en este ámbito. Sin embargo, las ideas progresistas de las décadas de los ‘ 60 y ‘70, momento en el que tuvo lugar la famosa reforma del sistema educativo, claramente formaron parte del clima de renovación política y cultural con tintes izquierdistas al que hacíamos referencia al principio.

Luego del debate político y las mociones presentadas por los miembros del parlamento finlandés en los '60, la Ley de Educación Básica que instauraba una reforma comprensiva, comenzó a regir a partir de 1968. El viejo sistema que estipulaba dos o tres tramos fragmentados fue reemplazado por un nuevo trayecto de nueve años de educación básica para todos los niños. Reformas similares ya habían comenzado a implementarse en países vecinos como Suecia y Noruega. La modalidad unificada de educación primaria y secundaria fue esparciéndose gradualmente alrededor de todo el país. El Comité Nacional de Educación designó este nuevo sistema hacia fines de los ' 60 y comienzos de los '70. A su vez, el período de renovación y transición entre 1972 y 1979 fue dirigido y organizado por la Agencia Nacional Finlandesa de Educación que controlaba la implementación de políticas en base a lo que se dictaba en las legislaciones. El proceso ha sido celebrado y considerado exitoso luego del desempeño finlandés en las pruebas internacionales de PISA en el siglo XXI (Sahlberg, 2013).

No podemos dejar de resaltar que el proceso parlamentario vivido en Finlandia (y en los demás países nórdicos antes mencionados) en los años ' 60 , difiere mucho del contexto político que se vivía en Brasil durante el tiempo de Freire. En Brasil, el gobierno progresista había sido derrocado en un golpe de Estado en 1964, luego de que la clase dominante y de élite (clase elitista económica, políticos de derecha y grandes empresarios) haya decidido poner freno al desarrollo del activismo político y la educación en las clases populares. Tal como lo dice el propio Freire (2002), las élites poderosas pensaron que las clases populares y los pobres no eran parte de la democracia y no podían "participar activamente en el proceso histórico". En los países nórdicos el contexto político era diferente: las reformas educativas y de cualquier otro tipo, se daban en base a debates políticos democráticos. El Estado de derecho (Rechtsstaat), establecido luego de la guerra civil en 1918, es la piedra angular de la sólida democracia parlamentaria en Finlandia. El mismo garantizó un clima pacífico en la sociedad finlandesa a lo largo del siglo XX.

Es importante, asimismo, contextualizar el nacimiento de la reforma de la escuela comprensiva y su éxito: era, definitivamente, mucho más que una reforma pedagógica. No era sólo un cambio curricular, o una 
modificación en los métodos de enseñanza sino una reforma comprensiva de justicia social e igualdad para todas y todos las y los estudiantes y sus familias.

\footnotetext{
El surgimiento de la escuela comprensiva fue parte de un desarrollo político mayor del sistema finlandés de seguridad social que incluye legislación para dar al común de la gente mayor libertad y mejorar su calidad de vida. Estas mejoras en los estándares básicos establecen una base firme para elevar la asistencia y los resultados escolares. Para que las niñas y niños se desempeñen bien en la escuela y disfruten del aprendizaje, es necesario tener una sociedad justa, segura y democrática (Renfors y Suoranta, 2018, p. 267).
}

Todas las y los estudiantes comenzaron a asistir a la escuela pública y común sin la posibilidad de alternativas privadas significativas. De esa manera, la educación unificó a las niñas y niños de familias pobres y ricas que ahora compartían escuelas y grupos. Esto incentivó la mejora de la calidad de la educación para todas y todos, no sólo para quienes podían pagar por ella: si los padres y madres de las clases medias y altas demandaban una mejor preparación académica para sus hijas e hijos, las niñas y niños de clases bajas y trabajadoras se beneficiaban por compartir el sistema y las mismas escuelas. El nuevo sistema escolar proveía textos y otros materiales de estudio de manera gratuita, así como transporte escolar, comidas diarias (de nuevo, pobres y ricos recibían la misma comida saludable en las escuelas) y un sistema universal de servicios de salud para estudiantes (que incluye cuidado dental). Al mismo tiempo, e igualmente importante, las políticas municipales de cuidado de la primera infancia se volvieron accesibles para todas las familias. Ambos, servicios de salud y sociales, fueron reformados -incluyendo, por ejemplo, ayuda financiera y beneficios para estudiantes de niveles secundario y terciario- (Jaakkola et al., 1994). Esto permitió a las personas luchar por una mejora en la calidad de vida (en los casos más típicos, buscando acceder a una mejor educación que la que tuvieron sus padres) sin distinción de la región, del lugar de residencia, sus recursos y de su historia familiar.

Estos avances, que llaman la atención por su progresismo cuando se los ve en retrospectiva, fueron posibles porque en ese particular momento Finlandia estaba gobernada por la coalición llamada "Frente del Pueblo" o "Frente Popular"; gobierno que estaba compuesto por representantes de los socialdemócratas, La Liga Democrática Popular de Finlandia (socialistas y comunistas) y el Partido del Centro, principalmente respaldado por el sector agrario. Dicha coalición contaba con el apoyo de múltiples organizaciones sociales de base y los movimientos progresistas de los años ' 60 y '70 que mencionamos anteriormente. Los partidos de izquierda lucharon por la igualdad en el sentido de movilidad social "vertical". En cambio, el Partido del Centro luchó por la igualdad y justicia "horizontal", es decir en un sentido geográfico, defendiendo las posibilidades de las y los jóvenes de las zonas rurales de tener un acceso igualitario a la escolarización, garantizando mayores oportunidades y calidad de vida, tal como ocurría en los espacios urbanos. Resulta interesante que el actual gobierno de Finlandia, asumido en 2019, esté compuesto por una coalición similar al Frente Popular, con la incorporación del Partido Verde. Sin embargo, tristemente, parece mucho más difícil lograr la implementación de estas transformaciones progresistas en el mundo actual.

No es una coincidencia que la educación transformadora y el pensamiento social hayan cobrado auge al mismo tiempo en distintos lugares del mundo. Las luchas que Paulo Freire y otros revolucionarios latinoamericanos llevaron adelante, son de distinto carácter que las reformas del sistema de asistencia social y la implementación de políticas socialdemócratas y de izquierda que tuvieron lugar en los países nórdicos. Aún así, ambas comparten una misma visión de la justicia social y un horizonte común de una sociedad mejor. Entonces, podemos pensar que hubo cierta familiaridad y semejanzas entre la pedagogía revolucionaria de Freire en el sur y la reforma educativa progresista en el norte, 50 años atrás. Ambas compartieron el mismo tipo de ideales de educación igualitaria y también se asemejaron en tanto pensaron que la justicia educativa siempre va de la mano de una preocupación más profunda y general de la justicia social.

Nos gustaría concluir con una historia de los años '70. Un joven maestro de una escuela elemental en Nolimo, una pequeña villa escasamente poblada que se ubica en los sectores rurales del norte de Finlandia, había comprado recientemente un ejemplar de Pedagogía del oprimido en su edición sueca. Cierto día, el maestro decidió regalarle esta copia a uno de sus mejores estudiantes, Voitto Kuosmanen, esperando 
que pudiera servirle como una "guía para la vida". Luego, ya en la escuela secundaria, Kuosmanen con sus compañeros leyeron el libro de Freire en un círculo de cultura que compartían para aprender el idioma sueco. No sólo leyeron la palabra escrita y aprendieron el idioma, sino que también tomaron conciencia y leyeron el mundo de una manera nueva y transformadora gracias a él.

El diálogo auténtico, la conciencia y la liberación de circunstancias o modelos de pensamiento y de conducta opresivos, tuvieron un importante impacto en la vida de estos jóvenes cuyos caminos, luego de terminar la secundaria, los fueron llevando al estudio y al trabajo en los sectores de la juventud, la sociedad, la salud y la educación. Freire nos invitó a un diálogo conjunto, a la liberación de la opresión y a la examinación crítica de nuestro pensamiento y nuestras acciones (Kuosmanen, 2016, p. 6).

\section{ReFERENCIAS}

Ahonen, T. (2004). Johdanto: kontekstuaalinen teologia [Introducción: teología contextual]. En T. Ahonen \& J. Komulainen (Eds.). Teologian ilmansuuntia. Helsinki: Gaudeamus

Ahteenmäki-Pelkonen, L. (1997). Kriittinen näkemys itseohjautuvuudesta. Systemaattinen analyysi Jack Mezirowin itseobjautuvuuskäsityksistä [Visión cítica del aprendizaje auto-motivado. Un análisis sistemático de la concepción de Jack Mezirow]. Helsinki: Universidad de Helsinki.

Aittola, T., Eskola, J. \& Suoranta, J. (Eds.) (2007). Kriittisen pedagogiikan kysymyksiä [Preguntas en la Pedagogía Crítica]. Tampere: Universidad de Tampere.

Anttila, E. (2003). A Dream journey to the unknown. Searching for dialogue in dance education. [Un viaje soñado hacia lo desconocido. En búsqueda del diálogo en a enseñanza de la danza] Disertación (Academia de teatro). Recuperada desde: https://helda.helsinki.fi/handle/10138/33789

Corander, A. (1993). Lähimmäisyys, yhteisöllisyys ja diakonia: raportti vapautuksen pedagogisesta diakoniakasvatuksen kokeiluprojektista [La humanidad, la comunidad y la diaconía: reporte sobre un proyecto de pedagogía de la liberación en la educación diacónica]. Helsinki: Diaconia College of Helsinki.

Darder, A. (2018). The Students Guide to Freire's Pedagogy of the Oppressed. [La guía del estudiante para Freire: Pedagogía del Oprimido]. London \& New York: Bloomsbury.

Engeström, Y. (1984). Oppimaan oppimisen edellytykset [Las condiciones para aprender a aprender]. Aikuiskasvatus, $4(2)$.

Freire, P. (2002). Education for Critical Consciousness. [Educación para la conciencia crítica]. New York: Continuum.

Freire, P. (2005). Sorrettujen pedagogiikka [Pedagogía del Oprimido]. Transl. Joel Kuortti. Ed. Tuukka Tomperi. Tampere: Vastapaino.

Fried, A. (1975). Kasvatus vapauteen - Paulo Freiren opetusmenetelmä [Educación para la libertad - El método de Paulo Freire]. Vartija, 87(4), 176-184.

Gadotti, M. (1994). Reading Paulo Freire: His Life and Work. Transl. John Milton. [Leyendo a Paulo Freire: Su vida y su obra]. Albany: SUNY Press.

Hannula, A. (1998). Tiedostaminen ja muutos Paulo Freiren ajattelussa. Systemaattinen analyysi Sorrettujen pedagogiikasta [Concientización y cambio en el pensamiento freireano. Análisis sistemático de la Pedagogía del Oprimido]. Tesis de posgrado. Universidad de Helsinki. Departamento de Educación.

Hannula, A. (2000a). Sorrettujen vai kaikkien ihmisten pedagogiikkaa? [¿Pedagogía para el oprimido o para todos?] Aikuiskasvatus, 20(3).

Hannula, A. (2000b). Tiedostaminen ja muutos Paulo Freiren ajattelussa. Systemaattinen analyysi Sorrettujen pedagogiikasta [Concientización y cambio en el pensamiento freireano. Análisis sistemático de la Pedagogía del Oprimido]. Disertación (Universidad de Helsinki). Recuperado desde http://ethesis.helsinki.fi/julkaisut/kas/ kasva/vk/hannula/tiedosta.pdf

Hannula, A. (2001). Kritiikin ja toivon pedagogi [Pedagogía de la crítica y la esperanza]. niin \& näin, 29(2). 
Hiilamo, H. (2010). Kuoleman listat: suomalaisten salainen apu Chilen vainotuille. [La lista de la muerte: la ayuda secreta de los finlandeses los perseguidos chilenos]. Helsinki: Otava.

Hiivala-Jakku, R. (1976). Freiren pedagogiikasta [En la pedagogía freireana]. Aikuis- ja nuorisokasvatuksen laitoksen julkaisuja 8. Tampere: Tampereen yliopisto.

Hintikka, A.-M. (2000). Erilaisesta oppijasta erinomaiseksi oppijaksi: kokemuksia erilaisesta opettamisesta ja erilaisesta oppimisesta [De un aprendiz distinto a un aprendiz excelente: experiencias de enseñanza y aprendizaje diferenciado]. Helsinki: Helsingin seudun erilaiset oppijat.

Jaakkola, J., Pulma, P., Satka, M. \& Urponen, K. (1994). Armeliaisuus, ybteisöapu, sosiaaliturva. Suomalaisen sosiaalisen turvan historia [La historia de la seguridad social finlandesa]. Helsinki: Sosiaaliturvan keskusliitto.

Jauhiainen, K., Juvas, K., Kairamo, K. \& Varsa, A. (1984). Nicaragua - maakatsaus [Nicaragua- revisión de un país]. Helsinki: La sociedad de Geografía para el Desarrolllo.

Kakko, L. (1988). Rauhankasvatus ja aikuiskasvatuksen mabdollisuudet [Educación para la paz y las posibilidades de la educación de adultos]. Tampere: Universidad de Tampere.

Karjalainen, A. (1993). Paulo Freiren pedagogiikka ala-asteella [La pedagogía de Paulo Freire en la escuela primaria]. Tesis de grado. Universidad de Oulu. Departamento de Formación docente.

Karppinen, L. \& Räisälä, E.-L. (2002). Arkipäivän kapinaa: YK-liiton maailmankansalaisen kypsyyskoe ja sen objaajat ybteiskunnallisen tiedostamisen ja toiminnan tukijoina [La redelidión diaria: Los exámenes y los instructores de la asociación de ciudadanía mundial de la ONU, como guía para la conciencia y la acción social]. Tesis de grado. Universidad de Oulu. Departamento de Educación y Formación Docente.

Kekkonen, H. (1993). Rauhan siltaa rakentamassa [Construyendo el puente de la paz]. Helsinki: Kirjapaja.

Kemppainen, H. (1996). Freire-pedagogiikka: "Biljaisuuden kulttuurissa elävien"kouluttamisesta yrittäjyyskasvatukseen [La pedagogía freireana: de enseñar a aquellos que viven en la "cultura del silencio" a la educación para el emprendedurismo]. Pori: Salario.

Kemppainen, H. (1997).Paulo Freire-pedagogiikka: tie elinikäiseen oppimiseen [La pedagogía de Paulo Freire: el camino al aprendizaje permanente]. Tesis de grado. Universidad de Tampere. Departamento de Educación.

Kemppainen, H. (1999). Kunnianosoitus Paulo Freirelle [Un tributo a Paulo Freire]. Aikuiskasvatus, 19(2), 174-177.

Kiilakoski, T., Tomperi, T. \& Vuorikoski, M. (Eds.) (2005) Kenen kasvatus? Kriittinen pedagogiikka ja toisinkasvatuksen mahdollisuus [¿La educación de quién? Pedagogía crítica y la posibilidad de educar de otra manera]. Tampere: Vastapaino.

Komulainen, K. (1990). Paulo Freiren dialektinen kasvatusfilosofia ja nykyinen kasvatustilanne [La filosofía dialéctica de Paulo Freire en la educación y la situación educativa actual]. In J. Hilpelä, E. Paakkola \& J. Suortti (Eds.). Kasvatusfilosofisia näkemyksiä kasvatuksen tutkimukseen [Miradas sobre la filosofía de la educación para la investigación en educación]. Oulu: Universidad de Oulu.

Kotilainen, S. (2004). Toimijaksi tietoverkoissa: raportti kansalaislähtöisen verkkoviestinnän mabdollisuuksista [Volverse un activista en las redes digitales: un reporte sobre las posibilidades de comunicación iniciada por los ciudadanos en la red]. Tampere: Universidad de Tampere.

Kuosmanen, V. (2016) Paulo Freire tuli kylään. Sosiaalipedagogiikka.fi. Disponible en http://www.sosiaalipedagogii kka.fi/paulo-freire-tuli-kylaan/

Kurki, L. (1991a). Latinalais-amerikkalaisen kasvatustieteen metodologisia erityispiirteitä [Características metodológicas especiales de las ciencias de la educación en Latinoamérica]. Kasvatus, 22(1), 57-61.

Kurki, L. (1991b). Persoonakeskeinen kasvatus [Educación personalista]. Tampere: Universidad de Tampere.

Kurki, L. (2000). Sosiokulttuurinen innostaminen. Muutoksen pedagogiikka [Activación sociocultural. Pedagogía para el cambio]. Tampere: Vastapaino.

Kurki, L. (2002). Persoona ja yhteisö. Personalistinen sosiaalipedagogiikka [Persona y comunidad. Pedagogía social personalista]. Jyväskylä: SoPhi.

Kurki, L. (2005). Sosiokulttuurinen innostaminen yhteisöjen rakentajana [Activación sociocultural como una construcción de comunidades]. In Kiilakoski, T., Tomperi, T. \& Vuorikoski, M. (Eds.), Kenen kasvatus? 
Kriittinen pedagogiikka ja toisinkasvatuksen mahdollisuus [¿La educación de quién? Pedagogía crítica y la posibilidad de educar de otra manera]. Tampere: Vastapaino.

Laakso, M. (1989). Steiner-, Freire- ja Freinet-menetelmien soveltamisesta peruskouluun: vaihtoehtopedagogiikan kurssilla olleiden opettajien mielipiteitä ja ongelmia [Utilizando los métodos de Steiner, Freire y Freinet en la escuela elemental: opiniones y problemas de los docentes que participaron en un curso de pedagogías alternativas]. Tesis de grado. Universidad de Turku. Departamento de Educación.

Lanas, M., Niinistö, H. \& Suoranta, J. (Eds.) (2008). Kriittisen pedagogiikan kysymyksiä 2 [Preguntas en Pedagogía Crítica 2]. Tampere: University of Tampere.

Lehtimaja, L. (2006). Freiren kyydissä [Paseando con Feire]. Helsinki: Like.

Matikainen, M. (1986). Dialogipedagogiikkaa vankilassa [Pedagogía dialógica en una cárcel]. Tesis de grado. Universidad de Helsinki, Departamento de Educación.

McLaren, P. (2000). Che Guevara, Paulo Freire and the Pedagogy of the Revolution. Lanham: Rowman \& Littlefield.

Moisio, O.-P. \& Suoranta, J. (Eds.) (2009). Kriittisen pedagogiikan kysymyksiä 3 [Preguntas en Pedagogía Crítica 3]. Tampere: Universidad de Tampere.

Paasonen, M. (2000). Katso. Kuuntele. Kokeile. Sorrettujen teatteri pedagogisena välineenä opettajankoulutuksessa [Mirar. Escuchar. Experimentar. El teatro del oprimido como una herramienta pedagógica en la formación docente]. Tesis de grado. Universidad de Oulu. Departamento de Formación Docente.

Pekama, H. (1998). Yhdessä oppien ja kriittisesti tiedostuen kohti tasa-arvoisempaa tulevaisuutta. Paulo Freiren pedagogiikka dialogi-käsitteen kautta tarkasteltuna [Aprendiendo juntos para la conciencia crítica hacia un futuro más equitativo. La pedagogía de Paulo Freire vista desde el concepto de diálogo]. Tesis de grado. Universidad de Oulu. Departamento de Formación Docente.

Pikkarainen, E. (1989). Tietoistuminen, vapautuminen, ibmistyminen [Conscientizarse, liberarse y humanizarse]. Tesis de grado. Universidad de Oulu. Departamento de Ciencias Conductuales.

Pikkarainen, E. (1992). Johdatusta Paulo Freiren pedagogiikkaan [Introducción a la pedagogía de Paulo Freire]. Material de enseñanza. Universidad de Oulu.

Pirttijärvi, J. (1998). Ystävyyttä ja solidaarisuutta [Amistad y solidaridad]. In J. Pakkasvirta \& J. Aronen (Eds.), Kahvi, pahvi ja tango. Suomen ja Latinalaisen Amerikan subteet [Café, cartón y tango. La relación de Finlandia y Latinoamérica]. Helsinki: Gaudeamus.

Raassina, A. (1990). Lukutaito ja kehitysstrategiat. Kolme vuosikymmentä Unescon lukutaitopolitiikkaa [Estrategias de alfabetización y desarrollo. Tres décadas de las políticas de alfabetización de Unesco]. Jyväskylä: Universidad de Jyväskylä.

Raunu, J. (2004). Vapautuksen teologiaa ja uskonnon vapaakauppaa Latinalaisessa Amerikassa [Teología de la liberación y libre circulación de la religión en Latinoamérica]. In T. Ahonen \& J. Komulainen (Eds.). Teologian ilmansuuntia [Direcciones de teología]. Helsinki: Gaudeamus.

Renfors, A. \& Suoranta, J. (2018). "Miracle on Ice. Sociological Understanding of the Finnish Schooling Model”. In P. McLaren, \& S. SooHoo (Eds.). Radical Imagine-Nation. Public Pedagogy \& Praxis. New York: Peter Lang. [Milagro en el Hielo. Una comprensión sociológica del modelo escolar finlandés].

Riekki J. (1999). Kahdet linssit - maailmaanorientoitumistavan tiedostamisen merkitys Augusto Boalin Sorrettujen teatterin metodin tiedostamis- ja toimintaprosessissa [Dos lentes - el significado de la consciencia orientada al mundo en los procesos de concientización y acción en el método de teatro del oprimido de Augusto Boal]. Tesis de grado. Universidad de Oulu. Departamento de Formación Docente.

Sahlberg, P. (2013). El cambio educativo en Finlandia. ¿Quépuede aprender el mundo? Buenos Aires: Paidós.

Saraneva, T. (1991). Oikeudenmukaisuuden nälkä. Vapautuksen teologian haaste meille [Hambre de justicia. El desafío para la teología de la liberación for justice]. Helsinki: Kirjapaja.

Ståhle, P. (1993). Pedagogisia vaihtoehtoja [Alternativas pedagógicas]. Helsinki: Universidad de Helsinki.

Suoranta, J. (2003). Kasvatus mediakulttuurissa [Educación en la cultura de los medios]. Tampere: Vastapaino.

Suoranta, J. (2005). Radikaali kasvatus [Educación radicalizada]. Helsinki: Gaudeamus. 
Suoranta, J. (2019). Paulo Freire: sorrettujen pedagogi [Paulo Freire: Pedagogía del Oprimido]. Helsinki: Into.

Suoranta, J. \& Ryynänen, S. (2014). Taisteleva tutkimus [Investigación Activista e Insurgente]. Helsinki: Into.

Suortti, J. (1999). Paulo Freire ja toiminnan pedagogiikka [Paulo Freire y la pedagogía de la acción]. In J. Suoranta (Ed.). Nuorisotyöstä seikkailukasvatukseen [De animación juvenil a educación para la aventura]. Tampere: Taju.

Swantz, M.-L. (2004). Aikani Afrikassa [Mi tiempo en África]. Helsinki: Ajatus-kirjat.

Söderlund, L. (2020). Mukana kuvassa. Valokuvaus vapautuksen välineenä [En la imagen. La fotografía como un Método de Liberación]. Helsinki: Universidad de Aalto. (Próximamente)

Tamminen-Piippo, S. (1988). Paulo Freiren pedagoginen ajattelu ja käytäntö ja niiden merkitys 1980-luvulla [El pensamiento y la práctica pedagógica de Paulo Freire, y sus significados en los años 80']. Tesis de Grado. Universidad de Tampere.

Toimintaan Freiren kanssa. Opas Sorrettujen pedagogiikkaan 2012, [Acción con Freire. Una guía hacia la Pedagogía del Oprimido]. Helsinki: Demokraattinen Sivistysliitto ry. Disponible en https://issuu.com/sippokahmi/docs /freire_korjattu

Tomperi, T. (2001). Paulo Freire ja kriittinen pedagogiikka [Paulo Freire y la pedagogía crítica]. niin \& näin, 29(2), 62.

Tomperi, T. (2005). Johdanto Paulo Freiren Sorrettujen pedagogiikkaan [Introducción a Pedagogía del Oprimido de Paulo Freire]. In P. Freire, Sorrettujen pedagogiikka [Traducción finesa de Pedagogía del Oprimido, primer edición]. Tampere: Vastapaino.

Tomperi, T. \& Suoranta, J. (2005). Sorrettujen jälkeen. Freiren kritiikistä, suomalaisesta vastaanotosta ja sovelluksista [Después del Oprimido. Sobre la teoría crítica, la recepción finlandesa y los usos de Freire]. In P. Freire, Sorrettujen pedagogiikka [Traducción finesa de Pedagogía del Oprimido, primer edición]. Tampere: Vastapaino.

Tuominen, V. (1975). Paulo Freiren vapauttavasta pedagogiikasta [Sobre la pedagogía liberadora de Paulo Freire]. Kasvatus, 6(3).

Tuominen, V. (1979a). Kansanopistoko freireläinen? [¿Es el centro de educación de adultos una institución freireana?] Kansanopisto, 51(5).

Tuominen, V. (1979b). Paulo Freiren vapauttavasta pedagogiikasta [Sobre la pedagogía liberadora de Paulo Freire]. Tesis de grado. Colegio de Joensuu, educación.

Veiga, E. (2019). Paulo Freire: como o legado do educador brasileiro é visto no exterior. BBC News Brazil. Disponible en https://www.bbc.com/portuguese/brasil-46830942

Vuola, E. (1991). Köyhien jumala. Johdatus vapautuksen teologiaan [Dios de los pobres. Introducción a la teología de la liberación]. Helsinki: Gaudeamus.

Vuola, E. (2008). Elossa vai kuollut? Katsaus latinalaisamerikkalaisen vapautuksen teologian nykytilaan [¿Vivo o muerto? Una reseña de la teología de la liberación en Latinoamérica hoy]. Teologinen Aikakauskirja.

Vuola, E. (2019). Ei enää risti ja miekka? Uskonto ja politiikka Latinalaisessa Amerikassa [¿El fin de la cruz y la espada? Religión y políticas en Latinoamérica]. In H. Pesonen, T. Sakaranaho \& S. Paukkunen (Eds.), Uskonto ja maailmanpolitiikka [Políticas religiosas e internacionales]. Helsinki: Gaudeamus.

\section{Notas}

1 N.de T.: El presente artículo, aunque fue escrito en inglés, recupera inevitables referencias del finés dada la nacionalidad de sus autores. Por lo tanto, nuestro propósito fue preservar el sentido original que los autores quisieron comunicar, volviéndolo asequible y comprensible para las lectoras y los lectores del español y respetando las relaciones semánticas y disciplinares tradicionales de nuestro lenguaje.

2 Uno de los autores (Juha Souranta) es pionero en la pedagogía crítica finlandesa y recientemente ha publicado una monografía de Freire (Souranta, 2019); el otro (Tuukka Tomperi) es especialista en filosofía de la educación y el editor de la traducción finesa de Pedagogía del oprimido(Freire, 2005) Este artículo fue elaborado en el marco del proyecto europeo INCASI, International Network for Comparative Analysis of Social Inequalities, financiado por el programa para la investigación y la innovación Horizon 2020 bajo Marie Skłodowska-Curie Actions (MSCA) No 691004 y 
coordinado por el Dr. Pedro López Roldán. Este artículo refleja la opinión de los autores. Las instituciones referidas no son responsables del uso que pueda hacerse de la información que contiene.

3 La pedagogía crítica angloamericana se desarrolló en estrecho vínculo con Freire y sus ideas. Muchas y muchos teóricos pedagógicos de origen latinoamericano, así como muchos investigadores europeos y norteamericanos, introdujeron las ideas de Freire a una amplia audiencia académica y educacional en el hemisferio norte - por ejemplo, Carlos Alberto Torres, Donaldo Macedo, Rosa Maria Torres, Peter McLaren, Henry Giroux, Paula Allman, Peter Mayo, Ira Shor, Bell Hooks, Antonia Darder, Glen Rikowski, Dave Hill, Mike Cole etc. Sobre las traducciones y publicaciones del trabajo de Freire, ver Gadotti (1994, pp. 71-82)

4 El reconocido trabajo de Jürgen Habermas, Erkenntnis und Interesse (Conocimiento e intereses humanos), incluye una distinción entre intereses técnicos, prácticos y emancipatorios del conocimiento. Fue publicado en 1968.

5 Materiales documentales contemporáneos sobre Finlandia, incluyendo ruedas de prensa y entrevistas, fueron compilados por la compañía finlandesa de emisión en la red, por ejemplo: https://yle.fi/aihe/artikkeli/2019/04/30/yh tenaista-kansaa-ei-voi-koskaan-voittaa-chilen-kansainvalinen

6 El álbum toma su nombre de una canción basada en la traducción del poema Almería de Pablo Neruda, ver: https://w ww.antiwarsongs.org/canzone.php?id=56759\&lang=en

7 Ver el artículo de Wikipedia y la foto de la escultura: https://en.wikipedia.org/wiki/Efter_badet

8 Para ejemplos ver la traducción finesa del libro de Peter McLaren Che Guevara, Paulo Freire y la Pedagogía de la revolución(Che Guevara, Paulo Freire ja vallankumouksen pedagogiikka, 2009), la introducción de Juha Suoranta a la teoría crítica de la educación Radikaali kasvatus(Educación Radical, 2005), un libro sobre los métodos de la investigación crítica (Suoranta \& Ryynänen, 2014) y libros que contienen principalmente artículos escritos por jóvenes académicos finlandeses en temas específicos de pedagogía crítica (Kiilakoski, Tomperi \& Vuorikoski, 2005; Aittola, Eskola \& Suoranta, 2007, Lanas, Niinistö \& Suoranta, 2008, Moisio \& Suoranta, 2009).

9 Entre los investigadores y académicos finlandeses que discuten y escriben sobre Freire, al menos los siguientes merecen mención: Fried (1975); Tuominen (1975, 1979a, 1979b); Hiivala-Jakku (1976); Engeström (1984); Matikainen (1986); Tamminen-Piippo (1988); Pikkarainen (1989, 1992); Komulainen (1990); Karjalainen (1993); Kemppainen (1996, 1997; 1999); Pekama (1998); Suortti (1999); Hannula (1998, 2000a, 2000b, 2001); Tomperi (2001, 2005); Tomperi \& Suoranta (2005); Suoranta (2019).

10 Ver https://paulofreirefinland.wordpress.com/ y http://www.kriittisetpedagogit.fi/

11 Vale la pena destacar que la traducción finesa no utilizó el término "educación/aprendizaje basado en problemas" a propósito, que solía ser una interpretación de las ideas de Freire en Finlandia tan común como desorientadora, porque frecuentemente se confundían con el método de enseñanza y aprendizaje "basado en problemas" (PBL). En cambio, utiliza la traducción literal de "educação problematizadora"/"educación problematizadora" (problematisoiva kasvatus in Finnish). En vez de aceptar al conocimiento y al mundo como algo dado, estable y carente de conflictos, se refiere a enseñanzas y aprendizajes que abordan la realidad como problemática, como algo que puede ser cuestionado y así transformado.

12 Sin embargo, hay algunas reseñas de distintas áreas, (por ejemplo, en tesis de grado y estudios de diplomatura), ver por ejemplo Matikainen (1986); Laakso (1989); Corander (1993); Karjalainen (1993); Ståhle (1993); Riekki (1999); Hintikka (2000); Paasonen (2000); Karppinen \& Räisälä (2002).

13 Ver, por ejemplo, la autobiografía de Kekkonen's (Kekkonen, 1993, pp. 112-220).

14 Ver, por ejemplo, Saraneva (1991); Vuola (1991, 2008, 2019).

15 Ver la página del editor sobre el libro (en finés): https://like.fi/kirjat/freiren-kyydissa/

\title{
CC BY-NC-SA
}

\section{INFORMACIÓN ADICIONAL}

\author{
Traducción a cargo de: Sol Maluendez y Amparo Tirado, Universidad Nacional de La Plata, Argentina ${ }^{1}$
}

